\title{
How to assess, diagnose, refer and treat adult obstructive sleep apnoea: a commentary on the choices
}

\section{Darren R Mansfield \\ MB BS, FRACP \\ Deputy Directo}

Nicholas A Antic

MB BS, FRACP, PhD, Clinical Director and Sleep and Respiratory Physician ${ }^{2,3}$

R Doug McEvoy MB BS, FRACP. Senior Director, ${ }^{2}$ and Professor of Medicine

1 Monash Respiratory and Sleep Medicine Monash Health,

Melbourne, VIC

2 Adelaide Institute fo Sleep Health

Repatriation General

Hospital, Adelaide, SA

3 Flinders University,

Adelaide, SA.

darren.mansfield@ southernhealth.org.au

MJA 2013; 199: S21-S26 doi: 10.5694/mjal3.10909

Online first 17/10/13 bstructive sleep apnoea (OSA) is a condition characterised by repetitive occlusions of the upper airway during sleep, resulting in arousals and sleep fragmentation. It impacts on daytime vigilance ${ }^{1}$ and contributes to cognitive dysfunction ${ }^{2}$ and mood disorders. ${ }^{3}$ It is a source of lost productivity in the workplace ${ }^{4}$ and increases motor vehicle accident risk. ${ }^{5}$ OSA has also been implicated as a cause of hypertension, ${ }^{6}$ with studies showing small but consistent falls in blood pressure following continuous positive airway pressure (CPAP) treatment. ${ }^{7}$ Epidemiological studies have also shown OSA to be independently associated with an increased risk of diabetes ${ }^{8}$ and cardiovascular disease, ${ }^{9,10}$ although definitive evidence for a causal link with these diseases awaits the results of large-scale randomised controlled trials of OSA treatment. In the early 1990s, the prevalence of OSA in the community in the United States, determined by polysomnography (PSG), was shown to be $24 \%$ of adult men and $9 \%$ of women, ${ }^{11}$ with recent evidence suggesting a further increase due to the obesity epidemic and an ageing population. ${ }^{12}$ OSA is now recognised as a major public health and economic burden, with an estimated cost to the Australian community of more than $\$ 5.1$ billion a year in health care and indirect costs. ${ }^{4}$

The purpose of this article is to describe the key issues in evaluation and management of OSA, to assist health care professionals to better engage in OSA management. We outline several evidence-based models of care that could be scaled up to allow the primary care physician to have a greater role in addressing the high burden of OSA in the community. To do this, primary care health professionals must be skilled in identifying those at high risk of OSA who are likely to benefit from treatment and must know which investigation to order, what treatments to recommend, and when specialist referral is needed.

\section{Polysomnographically determined versus clinically important OSA: telling the difference}

Despite the high prevalence of OSA, most patients are minimally symptomatic. About $15 \%$ of patients have moderate to severe sleep apnoea. ${ }^{13}$ The vital issue in clinical practice is to identify those with OSA who have clinically important disease. Lack of clarity around goals of treatment can lead to excessive investigation, inappropriate treatment and patient disengagement. We believe the major goals of management of OSA should be:

- to identify and offer treatment to symptomatic patients, regardless of disease severity, whose safety and quality of life is affected;

- to identify and offer treatment to patients with severe OSA determined by PSG, regardless of symptoms, who may be at risk of adverse health outcomes; and
- Obstructive sleep apnoea (OSA) determined by polysomnography is highly prevalent, affecting about $25 \%$ of men and $10 \%$ of women in the United States, although most have few or no symptoms.

- Symptomatic moderate to severe OSA has major health implications related to daytime sleepiness, such as increased accidents, altered mood and loss of productivity in the workplace. Severe OSA may increase the risk of cardiovascular disease independent of daytime sleepiness.

- A major challenge is to correctly identify, from the large community pool of disease, people with symptoms and those at risk of long-term complications.

- For treatment plans to achieve quality patient outcomes, clinicians must have a clear understanding of patients' symptoms and their motivations for presentation, and be knowledgeable about the evidence surrounding the health risks of OSA and the relative merits of the various diagnostic and treatment options available.

- The diagnosis of OSA represents a teachable moment to target adverse lifestyle factors such as excessive weight, excessive alcohol consumption and smoking, which may be contributing to OSA and long-term cardiometabolic risk.

- OSA assessment and management has traditionally involved specialist referral and in-laboratory polysomnography. However, these services may not always be easy to access.

- Controlled studies have shown that patients with a high pretest probability of symptomatic, moderate to severe OSA can be managed well in primary care, or by skilled nurses with appropriate medical backup, using simplified ambulatory models of care.

- The future of sleep apnoea assessment and management will likely include models of care that involve early referral to specialists of patients with complex or atypical presentations, and an upskilled and supported primary care workforce to manage symptomatic, uncomplicated, high pretest probability disease.

- to modify adverse lifestyle factors that contribute to OSA pathogenesis and other poor health outcomes. This may include advice on diet and exercise to lose weight, and encouragement to reduce alcohol intake and stop smoking.

\section{Personalised care plans on a public health scale - the challenges of meeting the burden of disease}

Optimal outcomes are usually achieved through an initial identification of the presenting clinical triggers, an evaluation of the symptom profile, and an exploration of the patient's treatment preferences and capacity to afford or comply with the range of treatment options. The workup for OSA must start with a careful clinical assessment to 
identify patients who are likely to benefit from treatment. Clinicians must then select an investigation: either inlaboratory PSG, home-based PSG or simplified limited channel sleep testing. The test result must then be coupled closely with the clinical assessment to inform a personalised treatment plan. This plan should identify adverse lifestyle factors, overlapping sleep disorders and medical comorbidities (eg, hypertension, diabetes, depression, dyslipidaemia), and consider these when advising on OSAspecific treatments. ${ }^{14}$ Box 1 depicts an algorithm that may assist the primary care practitioner with this process. There is no one preferred treatment for OSA but rather a range of options of proven effectiveness that can be applied individually or in combination, depending on patient preference, symptoms, OSA severity, comorbidities and other health risk factors (Box 2). Development of a personalised treatment plan requires the active involvement of the patient, partner and family in goal-setting. ${ }^{14}$ For the health professional, it requires that they be sufficiently familiar with the field and the practical application of each of the available OSA investigations and treatment options. The complexity of this process has meant that OSA has been traditionally managed by a relatively small specialised workforce using the gold standard, in-laboratory PSG. However, patient access to specialist sleep services has been limited and alone will not be able to cope with the evidently large burden of disease. ${ }^{12}$

\section{The emerging landscape}

Given these service barriers, various simplified, lower-cost clinical models have been developed for OSA. These have incorporated screening questionnaires to identify patients at high risk of OSA, ${ }^{15-19}$ simplified testing with homebased PSG or limited channel sleep studies (typically without sleep electroencephalography) and selected use of automatically titrating CPAP devices that lessen the need for supervised in-laboratory CPAP titrations. If patients are identified as having a high pretest probability of OSA and if major comorbidities and overlapping sleep disorders are excluded (Box 3), the use of home-based PSG or limited channel sleep testing and automatically titrating CPAP has been shown to produce similar or non-inferior patient outcomes to more traditional specialist referral and inlaboratory PSG approaches. ${ }^{20-23}$ Further, it has been shown that with suitable training and support from a specialist sleep centre, these management approaches can be applied effectively to uncomplicated OSA patients by nurses and primary care physicians. ${ }^{24}$

A major challenge is how to translate and upscale these research findings from controlled settings to the "real world" to meet the demonstrably high community burden of disease while ensuring high-quality, holistic patient care. The current availability of open-access PSG has enabled primary care practitioners to become more involved in the care of OSA patients. However, few of these services currently select for high pretest probability of disease, nor do they train or adequately support the referring health care professional to ensure that they are sufficiently knowledgeable in assessment and personalised treatment of OSA. Some patients accessing this service model who are found to have uncomplicated moderate to severe symptomatic OSA may adhere to CPAP treatment and be successfully managed in primary care. However, there are no data available on the overall adequacy of CPAP treatment for patients with milder or

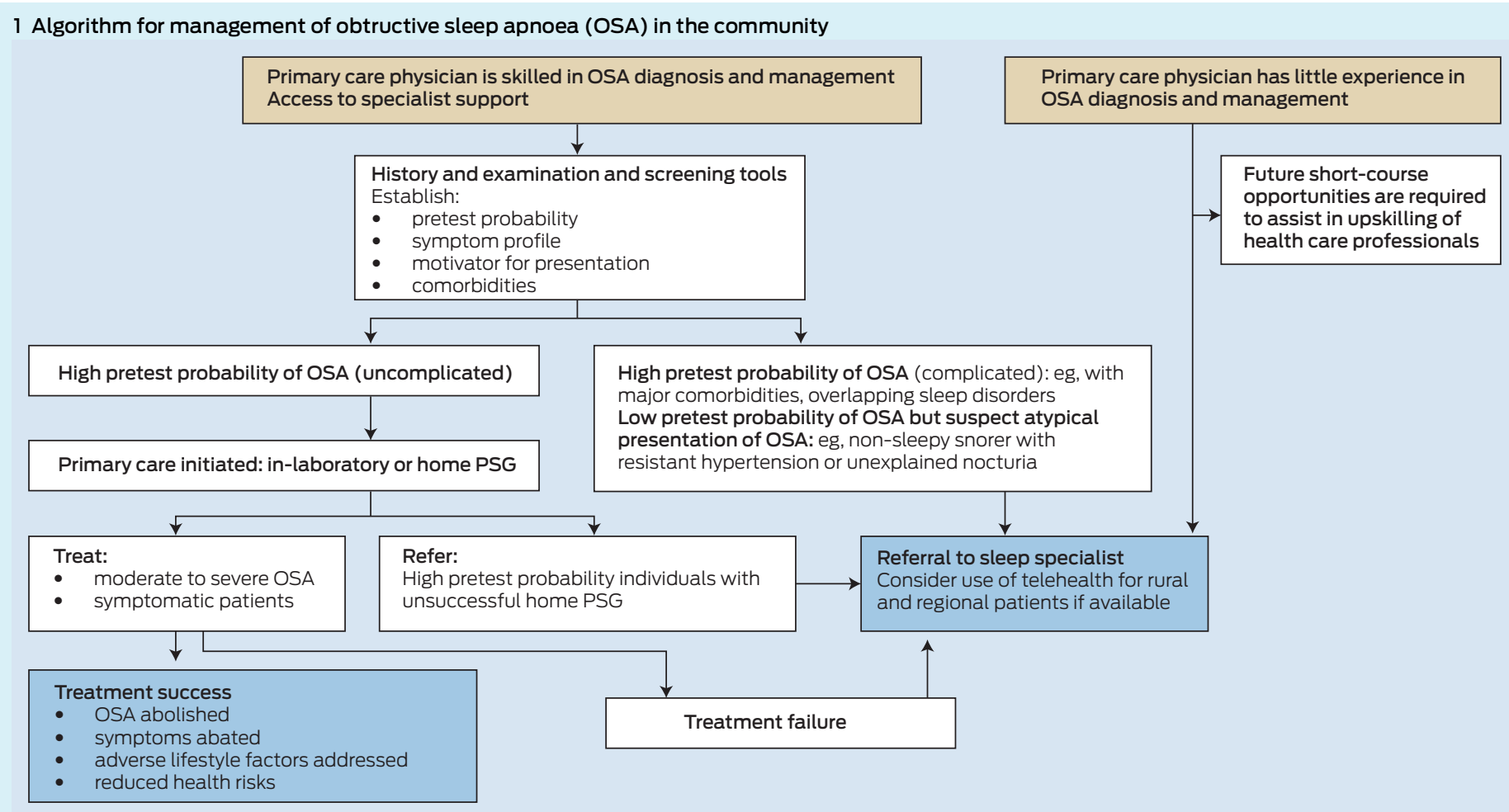

PSG = polysomnography. 


\begin{tabular}{|c|c|c|c|c|c|}
\hline Option & Optimal group & Cost & Trial option & Comfort & Comment \\
\hline Nasal CPAP & $\begin{array}{l}\text { Moderate to severe OSA; selected } \\
\text { mild cases; prominent symptoms; } \\
\text { high cardiovascular risk }\end{array}$ & $\$ 1000-\$ 2400$ & Yes - rental & $\begin{array}{l}\text { Variable - can be } \\
\text { uncomfortable }\end{array}$ & $\begin{array}{l}\text { Gold standard - most efficacious; } \\
\text { adherence variable }\end{array}$ \\
\hline MAS (custom fit) & $\begin{array}{l}\text { Primary snorers; mild to moderate } \\
\text { OSA; supine dominant OSA; some } \\
\text { severe cases; OSA and bruxism }\end{array}$ & $\$ 1200-\$ 2000$ & $\begin{array}{l}\text { No, but temporary } \\
\text { devices emerging }\end{array}$ & $\begin{array}{l}\text { Variable - can be } \\
\text { uncomfortable }\end{array}$ & \\
\hline $\begin{array}{l}\text { Nasal EPAP (single-night } \\
\text { use) }\end{array}$ & $\begin{array}{l}\text { Mild to moderate OSA; some severe } \\
\text { OSA }\end{array}$ & $\$ 3.50 /$ night & Yes & $\begin{array}{l}\text { Variable - can be } \\
\text { uncomfortable }\end{array}$ & Recent innovation - role emerging \\
\hline $\begin{array}{l}\text { Weight loss (stand-alone } \\
\text { therapy) }\end{array}$ & $\begin{array}{l}\text { Goal, } 10 \% \text { body weight; mild to } \\
\text { moderate OSA }\end{array}$ & Low & na & na & Low achievement rate \\
\hline Bariatric surgery & $\mathrm{BMI}>35 \mathrm{~kg} / \mathrm{m}^{2}$ & High & No & Medium & $\begin{array}{l}\text { Variable reduction in OSA; often } \\
\text { limited availability in public system }\end{array}$ \\
\hline Supine avoidance device & Supine OSA & Low & Yes & Comfortable & $\begin{array}{l}\text { Limited data on efficacy and } \\
\text { adherence }\end{array}$ \\
\hline Upper airway surgery & All ranges of OSA & High & na & Uncomfortable & $\begin{array}{l}\text { Salvage treatment for failed CPAP or } \\
\text { MAS }\end{array}$ \\
\hline Tonsillectomy & $\begin{array}{l}\text { Gross tonsillar hypertrophy; all } \\
\text { severities of OSA }\end{array}$ & High & na & Uncomfortable & $\begin{array}{l}\text { May have high cure rate if } \mathrm{BMI} \\
18.50-24.99 \mathrm{~kg} / \mathrm{m}^{2}\end{array}$ \\
\hline
\end{tabular}

complex OSA, or overlapping sleep disorders and adverse lifestyle issues. There is also a lack of such data for patients who refuse CPAP treatment or for whom the treatment is unsuccessful.

\section{Clinical assessment}

If sleep service delivery at the primary care level is to be upscaled and the recently validated simplified models of care for OSA translated into routine care, there will need to be greater awareness around clinical assessment, goals of OSA treatment and the various available treatment options. Objectives of the clinical assessment are to determine the motivating factor(s) for presentation and the patient's symptom profile and pretest probability of disease, and to identify modifiable adverse lifestyle factors and co-occurring sleep problems. Collectively, these factors will have an important influence on the investigation and management pathway.

\section{Why does a patient seek evaluation?}

Identifying the patient's motivations for seeking help will influence the treatment recommendation and likely adherence to therapy.

Patients present for three fundamental reasons:

- snoring causing social disruption or embarrassment;

- symptoms of unrefreshing sleep, daytime fatigue and sleepiness and its social or professional consequences;

- concerns that untreated sleep apnoea may contribute to adverse health outcomes.

\section{Pretest probability of disease}

The patient's and bed partner's reports combined with patient characteristics such as age, sex and body habitus help determine the pretest probability of OSA (Box 3). The initial assessment by the general practitioner or practice nurse can be assisted by the use of a simple 3-5 minute screening tool such as the OSA50 ${ }^{16}$ (Box 3) or Berlin ${ }^{17}$ questionnaires, which have been validated in the primary care setting, and can be followed by the 8-item Epworth
Sleepiness Scale questionnaire ${ }^{25}$ to further screen for excessive sleepiness and thus identify those most likely to benefit from treatment.

In general, straightforward, high pretest probability symptomatic OSA (Box 3) may be suited to clinical assessment, home-based PSG and treatment in primary care. A high pretest probability of OSA will improve accuracy for limited channel sleep testing and homebased PSG and reduce equivocal results that need repeating in the laboratory. Robust testing of this model of care has demonstrated favourable outcomes, ${ }^{24}$ however, it is predicated on primary care physicians and nurses having the necessary training to manage sleep disorders, being willing to engage in patients' management, and in having ready access to specialist backup when required. ${ }^{23}$ Unless the primary care physician has acquired considerable expertise, less clear-cut cases are best referred to a specialist early in the clinical pathway, as are patients with high pretest probability, and patients with overlapping sleep pathologies and serious medical comorbidities such as heart failure and chronic obstructive pulmonary disease.

\section{Clinical features of OSA}

There are nuances to sleep history-taking that, if appreciated, will further enhance the clinical assessment and improve the chances of identifying the high-risk patient and increase the likelihood of a favourable treatment outcome.

Snoring: impression of snoring severity can be obtained from its reported frequency (variable or habitual) positional nature, or association with alcohol. A collateral history from a bed partner, if available, can assist although the description will be influenced by their tolerance levels. More severe snoring is associated with a dry or even painful throat in the morning. While chronic loud snoring is one of the most reliable pointers to OSA, the absence of a snoring history does not rule it out. Bed partners may be absent or unreliable, and silent forms of OSA exist. 
Witnessed apnoeas: partner reports of breathing pauses during sleep, when available, are a useful guide to the presence of OSA. OSA patients are rarely aware themselves of apnoeic events, but when this occurs the patient may describe that snoring woke them, sometimes with a brief palpitation or sense of transient breathlessness. More prolonged choking to full wakefulness should prompt consideration of other causes such as nocturnal laryngospasm, an alarming but non-fatal symptom often triggered by gastro-oesophageal reflux. Reflux is more prevalent in OSA ${ }^{26}$ so both forms of nocturnal choking may coexist.

Unrefreshing sleep and daytime sleepiness: contrary to conventional wisdom, excessive daytime sleepiness has been shown to have low discriminatory power for predicting OSA. ${ }^{16}$ Community studies of OSA have generally found low rates of associated sleepiness and, when OSA is present, other causes including depression, sedative medication and inadequate sleep duration need to be considered. ${ }^{27}$ Nonetheless, sleepiness in someone with proven OSA is a key consideration in determining the need for treatment.

OSA-related sleepiness is classically unrelated to sleep duration and should be distinguished from fatigue, an overlapping but less specific symptom. It is most pronounced in passive situations and enquiry should target these, including lunch breaks, meetings, seminars, watching television and driving (particularly long-distance driving or travelling as a passenger). Some patients avoid situations that induce sleepiness and thus do not spontaneously volunteer this symptom. Others are reluctant to self-report sleepiness because of perceived negative consequences for their driver's licence or occupation. The Epworth Sleepiness Scale (Box 3) is a validated and useful clinical guide for quantifying subjective sleepiness, ${ }^{25}$ which assists but does not replace history-taking.

\section{Investigation: home-based versus in-laboratory PSG}

In Australia, Medicare reimbursement is provided for full PSG, conducted in either supervised (in-laboratory) or unsupervised (home) settings. For home-based PSG, patients are connected to the electrodes and sensors at the facility on the afternoon of the test and return home, or self-connect in their own home before bed, according to written, verbal or audiovisual instructions. Patients may perceive an increased level of convenience and comfort with testing in their own home, sensing a more sleep-conducive environment. When directly compared, one study showed $50 \%$ of patients preferred homebased testing, 25\% preferred laboratory-based testing and $25 \%$ had no preference. ${ }^{28}$ Comparison of homebased versus in-laboratory PSG showed reduced total cost for home testing ${ }^{28}$ and high overall satisfaction rates for both forms of testing. ${ }^{28}$ However, home-based PSG is associated with higher test-failure rates, partial signal loss producing equivocal results, ${ }^{28,29}$ and a tendency to underestimate sleep apnoea severity. ${ }^{29}$ More severe sleep apnoea (high pretest probability) may overcome the shortfalls of partial signal loss and any tendency to underestimate severity, and this will improve diagnostic accuracy.

\section{Limited channel ambulatory sleep testing}

Limited channel devices dispense with electroencephalographic measurements of sleep and rely on one to four channels of respiratory data to assess the frequency and severity of disordered breathing events. The signals may include finger pulse oximetry and thoracic and abdominal impedance bands to assess respiratory efforts and oronasal airflow. One concern is that dispensing with direct measurements of sleep will underestimate OSA severity for patients with short sleep duration. However, there is reasonably good agreement between these simplified devices and inlaboratory PSG in measuring the frequency of disordered breathing events, and professional guidelines have given qualified support to their use. ${ }^{30}$ As with home-based full PSG testing, their successful application requires careful screening to first establish a high pretest probability of disease, followed by test interpretation and treatment advice by suitably trained professionals with specialist backup, including further in-laboratory testing if required.

In Australia, there is no Medicare reimbursement for limited channel sleep testing, restricting its availability. Currently, this type of testing tends to be offered directly to the patient at various outlets and pharmacies linked to the potential sale of CPAP and other therapeutic devices, sometimes bypassing the medical profession entirely.

\section{Obstructive sleep apnoea: simple questionnaire determinants of pretest probability and symptom profile \\ OSA50 15}

Determinant

Question

If yes, score*

$\begin{array}{lll}\text { Obesity } & \text { Is your waist circumference }{ }^{\dagger}>102 \mathrm{~cm}(\mathrm{men}), \\ & >88 \mathrm{~cm} \text { (women)? } \\ \text { Snoring } & \text { Has your snoring ever bothered other people? } \\ \text { Apnoea } & \begin{array}{l}\text { Has anyone noticed that you stopped breathing } \\ \text { during sleep? }\end{array} \\ 50 & \text { Are you aged } 50 \text { years or over? }\end{array}$

Maximum total

score

* In Chai-Coetzer et al, ${ }^{16}$ an OSA50 score $\geqslant 5$ was $100 \%$ sensitive $(95 \% \mathrm{Cl}, 86 \%-100 \%)$ for moderate to severe OSA (ie, detected all cases) and an OSA50 score $<5$ had high negative predictive value $(100 \%$ [ $95 \% \mathrm{Cl}, 73 \%-100 \%])$. However, the positive predictive value of the test was relatively modest ( $48 \%[95 \% \mathrm{Cl}, 35 \%-63 \%])$, indicating that while it can be used to increase the pretest probability of OSA, patients who have a positive score $(>5)$ need to have a sleep study to definitively establish the diagnosis. † Measured at the level of the umbilicus.

\section{Epworth Sleepiness Scale (ESS) ${ }^{25}$}

How likely are you to doze off or fall asleep in the following situations, in contrast to feeling just tired? This refers to your usual way of life in recent times. Even if you have not done some of these things recently, try to work out how they would have affected you. Use the following scale to choose the most appropriate number for each situation:

Situation

Chance of dozing (score)*

\section{Sitting and reading}

Watching television

Sitting inactive in a public place (eg, a theatre or meeting)

As a passenger in a car for an hour without a break

Lying down to rest in the afternoon when circumstances permit

Sitting and talking to somebody

Sitting quietly after a lunch without alcohol

In a car, while stopped for a few minutes in traffic

$* 0=$ no chance of dozing 1 = slight chance of dozing $2=$ moderate chance of dozing $\cdot 3=$ high chance of dozing. The ESS is a guide only. An ESS score $>10$ is indicative of pathological daytime sleepiness. It is not a strong independent predictor of the presence of OSA; however, in established OSA, it is a predictor of response to treatment. Patients with lower scores (eg, 8-10) may also have mild impairment of vigilance in the day and should be evaluated. 
The evidence suggests that most modes of testing for OSA have a role when supported by a validated model of care. Currently in Australia, the extent to which sleep testing is coupled to an evidence-based model of care that ensures good patient outcomes varies widely. This situation is in part determined by the reimbursement scheme for testing and the regulatory framework.

\section{Treatment, treatment failures and the disengaged patient}

A comprehensive overview of all treatment options is beyond the scope of this manuscript, and international guidelines are available. ${ }^{31}$ Options are summarised in Box 2. Identification of sleep apnoea is a teachable moment for the health care professional to guide the patient and suggest interventions to modify lifestyle and reduce weight. Thereafter, treatment considerations ought to extend beyond CPAP. Studies have shown large variation $(17 \%-71 \%)$ in adherence to optimal CPAP (defined as average of $\geqslant 4$ hours per night). ${ }^{32}$ More recent randomised controlled trial evidence suggests that mandibular advancement splints may be as effective as CPAP across a range of OSA severity, ${ }^{33}$ although there is limited information on longer-term compliance. Newer surgical techniques are emerging for OSA and the combination of uvulopalatopharyngoplasty, tonsillectomy where appropriate, and a low-morbidity technique to reduce tissue volume at the tongue base shows promise in highly selected patients for whom conventional therapies such as CPAP or a mandibular advancement splint have been unsuccessful. ${ }^{34}$ Adults with gross tonsillar hypertrophy and sleep apnoea are uncommon but often do very well following tonsillectomy. Some preliminary success is reported with nasal positive expiratory pressure devices, ${ }^{35}$ although long-term adherence to treatment is unknown and patient selection needs more evaluation.

Overall, treatment for OSA includes a range of options, all of which have their unique challenges. Cost is a consideration and commitment is required to achieve long-term adherence. There is a risk that patients may not persevere with the treatment plan if the clinical assessment was not patient-focused and did not address key presenting symptoms or motivators. A negative experience has consequences in terms of lost opportunity if the patient withdraws from the therapeutic process. All patients should be clinically reassessed after a treatment option is tried, to ensure the treatment has been effective in controlling both OSA and its symptoms.

\section{The future}

The specialty of sleep medicine now has a robust curriculum, encompassing both respiratory and non-respiratory sleep disorders, and requires a full year of dedicated training. This will see larger numbers of specialists with sufficient skills to assist with managing the public health burden of OSA. Telehealth will also enable sleep specialists to assist health care practitioners and patients in rural and regional communities.
However, the large burden of disease is likely to be best served in the long term by an expanded trained pool of primary care and other health care providers working alongside sleep and respiratory specialists. In this model of care, sleep specialists working in a multidisciplinary environment would have as their major clinical focus complex or atypical OSA cases (eg, those with comorbidities or overlapping sleep disorders) or treatment failures. All modalities of sleep testing will be used in accordance with existing validated algorithms. These models of care will take time to evolve and will require changes to clinical guidelines and accreditation standards, the upskilling of the health care workforce, and government and private sector policy changes with respect to reimbursement.

Competing interests: Nicholas Antic has received a grant of $\$ 5$ million from Philips Respironics for a large randomised controlled trial of CPAP therapy for obstructive sleep apnoea, with equipment donations from Philips Respironics, ResMed, and Fisher and

Paykel. He has received additional equipment donations from ResMed, Philips Respironics and SomnoMed, and lecture fees and payment for development of educational presentations from ResMed. Doug McEvoy has received unconditional grants for sleep research from Philips Respironics and Fisher and Paykel, unconditional equipment grants for research studies from ResMed, Philips Respironics and Air Liquide Australia, and lecture fees from Philips Respironics.

Provenance: Commissioned by supplement editors; externally peer reviewed.

Received 11 Jul 2013, accepted 25 Aug 2013.

1 Guilleminault C, Partinen M, Quera-Salva MA, et al. Determinants of daytime sleepiness in obstructive sleep apnea. Chest 1988; 94: 32-37.

2 Salorio CF, White DA, Piccirillo J, et al. Learning, memory, and executive control in individuals with obstructive sleep apnea syndrome. J Clin Exp Neuropsychol 2002; 24: 93-100.

3 McCall WV, Harding D, O'Donovan C, et al. Correlates of depressive symptoms in patients with obstructive sleep apnea. J Clin Sleep Med 2006; 2: 424-426.

4 Deloitte Access Economics. Re-awakening Australia: the economic cost of sleep disorders in Australia, 2010. Canberra, Australia: Deloitte Access Economics, 2011. http://www.sleephealthfoundation.org.au/pdfs/news/ Reawakening\%20Australia.pdf (accessed Sep 2013).

5 Stutts JC, Wilkins JW, Scott Osberg J, et al. Driver risk factors for sleep-related crashes. Accid Anal Prev 2003; 35: 321-331.

6 Peppard PE, Young T, Palta M, Skatrud J. Prospective study of the association between sleep-disordered breathing and hypertension. NEngl J Med 2000; 342: 1378-1384

7 Bazzano LA, Khan Z, Reynolds K, et al. Effect of nocturnal nasal continuous positive airway pressure on blood pressure in obstructive sleep apnea. Hypertension 2007; 50: 417-423.

8 Wang X, Bi Y, Zhang Q, Pan F. Obstructive sleep apnoea and the risk of type 2 diabetes: a meta-analysis of prospective cohort studies. Respirology 2013; 18 : 140-146.

9 Punjabi NM, Caffo BS, Goodwin JL, et al. Sleep-disordered breathing and mortality: a prospective cohort study. PLOS Med 2009; 6: el000132.

10 Marin JM, Carrizo SJ, Vicente E, et al. Long-term cardiovascular outcomes in men with obstructive sleep apnoea-hypopnoea with or without treatment with continuous positive airway pressure: an observational study. Lancet 2005; 365: 1046-1053.

11 Young T, Palta M, Dempsey J, et al. The occurrence of sleep-disordered breathing among middle-aged adults. NEngl J Med 1993; 328: 1230-1235.

12 Adams RJ, Piantadosi C, Appleton SL, et al. Investigating obstructive sleep apnoea: will the health system have the capacity to cope? A population study. Aust Health Rev 2012; 36: 424-429.

13 Stradling JR, Crosby JH. Predictors and prevalence of obstructive sleep apnoea and snoring in 1001 middle aged men. Thorax 1991; 46: 85-90.

14 Heatley EM, Harris M, Battersby M, et al. Obstructive sleep apnoea in adults: a common chronic condition in need of a comprehensive chronic condition management approach. Sleep Med Rev 2013; 17: 349-355.

15 Chai-Coetzer CL, Antic NA, McEvoy RD. Ambulatory models of care for obstructive sleep apnoea: diagnosis and management. Respirology 2013; 18: 605-615.

16 Chai-Coetzer CL, Antic NA, Rowland LS, et al. A simplified model of screening questionnaire and home monitoring for obstructive sleep apnoea in primary care. Thorax 2011; 66: 213-219.

17 Netzer NC, Stoohs RA, Netzer CM, et al. Using the Berlin Questionnaire to identify patients at risk for the sleep apnea syndrome. Ann Intern Med 1999; 131: 485-491.

18 Chung F, Yegneswaran B, Liao P, et al. STOP questionnaire: a tool to screen patients for obstructive sleep apnea. Anesthesiology 2008; 108: 812-821. 
19 Mustafa M, Erokwu N, Ebose I, et al. Sleep problems and the risk for sleep disorders in an outpatient veteran population. Sleep Breath 2005; 9: 57-63.

20 Mulgrew AT, Fox N, Ayas NT, et al. Diagnosis and initial management of obstructive sleep apnea without polysomnography: a randomized validation study. Ann Intern Med 2007; 146: 157-166.

21 Berry RB, Hill G, Thompson L, et al. Portable monitoring and autotitration versus polysomnography for the diagnosis and treatment of sleep apnea. Sleep 2008; 31: 1423-1431.

22 Kuna ST, Gurubhagavatula I, Maislin G, et al. Noninferiority of functional outcome in ambulatory management of obstructive sleep apnea. Am J Respir Crit Care Med 2011; 183: 1238-1244.

23 Antic NA, Buchan C, Esterman A, et al. A randomized controlled trial of nurseled care for symptomatic moderate-severe obstructive sleep apnea. Am J Respir Crit Care Med 2009; 179: 501-508

24 Chai-Coetzer CL, Antic NA, Rowland LS, et al. Primary care vs specialist sleep center management of obstructive sleep apnea and daytime sleepiness and quality of life: a randomized trial. JAMA 2013; 309: 997-1004.

25 Johns MW. A new method for measuring daytime sleepiness: the Epworth sleepiness scale. Sleep 1991; 14: 540-545.

26 Shepherd KL, James AL, Musk AW, et al. Gastro-oesophageal reflux symptoms are related to the presence and severity of obstructive sleep apnoea. J Sleep Res 2011; 20 (1 Pt 2): 241-249.

27 Bixler EO, Vgontzas AN, Lin HM, et al. Excessive daytime sleepiness in a general population sample: the role of sleep apnea, age, obesity, diabetes, and depression. J Clin Endocrinol Metab 2005; 90: 4510-4515.
28 Rosen CL, Auckley D, Benca R, et al. A multisite randomized trial of portable sleep studies and positive airway pressure autotitration versus laboratorybased polysomnography for the diagnosis and treatment of obstructive sleep apnea: the Home PAP study. Sleep 2012; 35: 757-767.

29 Campbell AJ, Neill AM. Home set-up polysomnography in the assessment of suspected obstructive sleep apnea. J Sleep Res 2011; 20 (1 Pt 2): 207-213.

30 Collop NA, Anderson WM, Boehlecke B, et al. Clinical guidelines for the use of unattended portable monitors in the diagnosis of obstructive sleep apnea in adult patients. Portable Monitoring Task Force of the American Academy of Sleep Medicine. J Clin Sleep Med 2007; 3: 737-747.

31 Epstein LJ, Kristo D, Strollo PJ Jr, et al. Clinical guideline for the evaluation, management and long-term care of obstructive sleep apnea in adults. J Clin Sleep Med 2009; 5: 263-276.

32 Weaver TE, Grunstein RR. Adherence to continuous positive airway pressure therapy: the challenge to effective treatment. Proc Am Thorac Soc 2008; 5: 173-178.

33 Phillips CL, Grunstein RR, Darendeliler MA, et al. Health outcomes of continuous positive airway pressure versus oral appliance treatment for obstructive sleep apnea: a randomized controlled trial. Am J Respir Crit Care Med 2013; 187: 879-887.

34 MacKay SG, Carney AS, Woods C, et al. Modified uvulopalatopharyngoplasty and coblation channeling of the tongue for obstructive sleep apnea: a multicentre Australian trial. J Clin Sleep Med 2013; 9: 117-124.

35 Rosenthal L, Massie CA, Dolan DC, et al. A multicenter, prospective study of a novel nasal EPAP device in the treatment of obstructive sleep apnea: efficacy and 30-day adherence. J Clin Sleep Med 2009; 5: 532-537. 